\title{
WDM EDFA+RFA Hybrid Amplifier for Gain Equalization in C Band
}

\author{
Akchita Khemariya \\ M.tech Scholar \\ Department of Electronics and \\ Communication \\ SSET, SHIATS, Allahabad
}

\author{
Aditi Agrawal \\ Assistant Professor \\ Department of Electronics and \\ Communication \\ SSET, SHIATS, Allahabad
}

\author{
A.K. Jaiswal \\ Professor and Head \\ Department of Electronics and \\ Communication \\ SSET, SHIATS, Allahabad
}

\begin{abstract}
To sum up the advantages and counterbalance the drawbacks of various optical amplifier types, a hybrid amplifier can be made. Here a combination of two most popular and frequently used amplifiers i.e. EDFA-RFA i.e. Erbium Doped Fiber Amplifier altogether with Raman Fiber Amplifier; has been used to calculate the lowest gain variation in $\mathrm{C}$ band i.e. from $1530 \mathrm{~nm}$ to $1552.18 \mathrm{~nm}$ with $-24 \mathrm{dBm}$ input power using NRZ modulation format. In this paper, optimization of the length of EDFA is done. Also the gain variation and noise figure for various values of pump wavelengths and pump power is analyzed. The obtained results showed better gain flattening with four pumps RFA with value of gain ratio reducing to 0.692 with tolerable NF.
\end{abstract}

\section{Keywords}

EDFA, RFA, WDM, NF, DWDM, PON, NRZ.

\section{INTRODUCTION}

Revolution in information means that multimedia networks need large bandwidth with minimum loss in communication links that can be easily achieved with optical fiber as the transmission medium. [1] For long haul optical fiber communication optical amplifier is the main element of the transmission system. The advancement in the optical fiber communications has given rise to more powerful and efficient optical amplifiers which saves time, cost and power by eliminating the need to convert from optical to electrical or vice-versa [2].After the invention of Erbium Doped Fiber Amplifier there has been increase in data transfer capacity due to the use of WDM in optical communication. In fact as the need of wide broadband increased the researchers started utilizing the gain equalizing multi wavelength pumps RFA's. Hybrid amplifiers especially multi-pumped Raman amplifier enhances the global gain flatness mainly due to the optimization of the parameters of hybrid amplifier with the method PSO. Particle Swarm Optimization (PSO) allows optimization of multiple parameters at a time. Thus it is a faster method to get the best values of the parameters in Hybrid amplifiers. EDFA-RFA has advantages of both EDFA and RFA amplifiers [3].

Singh et al. [4] analyzed and compared multi-terabits DWDM system using hybrid amplifiers (EDFA-RFA) for various data formats such as NRZ, RZ, and DPSK. The result shows that RZ performed better in $64 \times 10$ and 96x 10 Gbps DWDM system comprising of hybrid optical amplifier. Kaler et al. [5] optimized the hybrid optical amplifier by using different parameters as Noise Figure and output power. They compared the performance of the system at different values of dispersions. The system achieves maximum of $70 \mathrm{~km}$ of distance at maximum dispersion of $16 \mathrm{ps} / \mathrm{nm} / \mathrm{km}$. Kaur et al. [6] investigated a $10 \mathrm{Gbps}$ WDM system at 16, 32 and 64 channels with various types of amplifiers. Comparison has been done using one amplifier at a time with respect to dispersion and transmission distance with or without nonlinearity. The analysis results in EDFA performing better than the SOA when dispersion is increased. RFA provides better gain flattening in L- Band with reduced non-linearity.

Bobrovs et al. [7] considered SOA-RFA and EDFA-RFA combination of hybrid amplifiers; after analyzing the eye diagrams for maximum transmission distances, EDFA-RFA turns out to be better as it produces less distortion than the SOA-RFA in a DWDM system. Singh et al. [8] analyzed the placement of RFA-EDFA hybrid amplifiers in fiber link. The results based on BER, output power and eye diagram for post, pre- and symmetrical power compensation methods were compared. Post power compensation method results in lowest BER and highest output power.Hsu et al. [9] studied theoretically the malfunction of $\mathrm{C}+\mathrm{L}$ band in hybrid amplifiers. They concluded that loop back scheme hybrid amplifiers may have many applications in WDM Long haul optical systems.

In this Paper setup of the simulation is of 16 channel WDM system in $\mathrm{C}$ band. The wavelength range is from $1530 \mathrm{~nm}$ to $1552.18 \mathrm{~nm}$ with channel spacing of $-0.2 \mathrm{GHz}$. For this range the input power is $-24 \mathrm{dBm}$, bit rate is $1 \mathrm{Gbit} / \mathrm{sec}$ having modulation format as NRZ. The system is analyzed using Optisystem 13.1 software of Optiwave. With this setup hybrid amplifier EDFA-RFA is used to get the lowest gain variation by changing the values of the four pump wavelengths in accordance to the constant pump power. Moreover, the number of pumps is increased with the help of laser pump arrays to 6 from 4 to compare the performance of the hybridamplifiers. Four pump RFA turned out to be better than the 6 pump RFA in terms of reduced gain ratio and less NF 


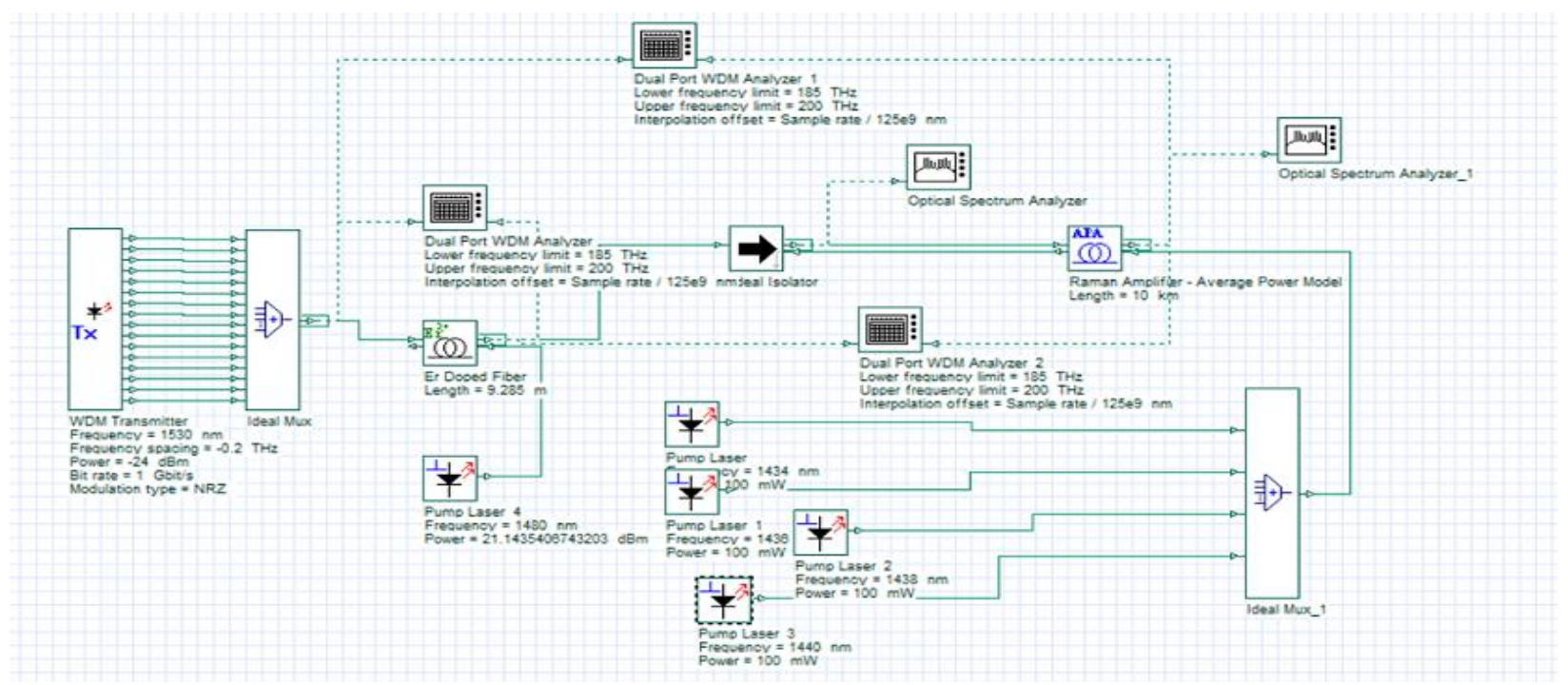

Figure 1: Schematic of simulation setup for hybrid amplifiers

\section{HYBRID EDFA-RFA}

In this 16 channel WDM system first the placement of EDFA is done, after which Raman amplifier is used as seen in the fig. 1. Both the amplifiers are inline amplifiers. It can be observed from the table that inline EDFA results in higher gain variation and less NF with $980 \mathrm{~nm}$ pump wavelength than with $1480 \mathrm{~nm}$ with equal pump power. Hence pumping wavelength of $1480 \mathrm{~nm}$ is better for gain equalization as it gives less gain variation. Through Single Parameter Optimization (SPO) technique, the length of EDFA is optimized and the resultant length is $9.2855 \mathrm{~m}$ with pump power of $130.123 \mathrm{mw}$ for maximum gain at counter pump of $1480 \mathrm{~nm}$ also provided different pump power from 100 to 200 mw. Ahead of the EDFA is $10 \mathrm{~km}$ Raman amplifier with four counter pump wavelengths. In this setup simulation is done by shifting the pump wavelengths at constant pump power to check the results. Effect of varying pump power is observed for same values of pump wavelengths. Also effect of increase in pump power with constant pump wavelengths is seen. Moreover effect of change in number of pumps with the changing pump power and wavelengths are observed. Here four pump, six pump RFA is considered.

Table no. 1. Comparison of EDFA and RFA individually as inline amplifiers

\begin{tabular}{|l|l|l|l|l|}
\hline $\begin{array}{l}\text { Inline } \\
\text { Amplifi } \\
\text { er }\end{array}$ & $\begin{array}{l}\text { Pump } \\
\text { Wavelength } \\
(\mathrm{nm})\end{array}$ & $\begin{array}{l}\text { Pump } \\
\text { Power } \\
(\mathrm{mw})\end{array}$ & $\begin{array}{l}\text { Gain } \\
\text { Variation } \\
(\mathrm{dB})\end{array}$ & $\begin{array}{l}\text { Noise } \\
\text { Figure } \\
(\mathrm{dB})\end{array}$ \\
\hline EDFA & 980 & 500 & 8.72 & 2.69 \\
\cline { 2 - 5 } & 1480 & 500 & 2.95 & 3.96 \\
\hline RFA & $\begin{array}{l}1448,1450,1 \\
452 \quad \text { and }\end{array}$ & $\begin{array}{l}200,200, \\
100 \text { and } \\
100\end{array}$ & 1.866 & $1.96-$ \\
& $1454 \quad$ & 2.65 \\
\hline
\end{tabular}

\section{RESULT AND DISCUSSION}

A. When pump wavelengths are varied with respect to constant pump powers:

From case 1 to case 5 in the table 3, it can be observed that as the pump wavelengths are increasing the gain variation is reducing. And then at case 3 the gain ratio is minimum, Thus giving gain flattening. When the pump wavelengths are increased more the gain ratio starts increasing again. This can be observed through Figure 2 and 3 which shows Gain and
NF with respect to wavelengths according to the cases mentioned in table 2. The value of pump wavelengths is 13 $\mathrm{THz}$ more from the WDM wavelengths to get more gain flattening.

B. When the pump powers are varied with constant pump wavelengths:

From case 6 to case 10 the pump power is kept same for all the pump wavelengths in a single case. It can be observed that the decrease in the pump power from 200 to 50 decreases the gain ratio but the noise figure ratio varies only slightly. Although low power gives less gain ratio but it decreases the value of gain significantly. Therefore case 9 results in better gain with good gain ratio. This can be observed through Figure 4 and 5 which shows Gain and NF with respect to wavelengths according to the cases mentioned in table 3 .

C. When the number of pumps are increased with varied pump powers:

In table 4 it can be observed that the decrease in the pump power decreases the gain ratio but as the pump power increases, the gain ratio increases which provides less gain flattening than seen in four pump RFA.

Table 2: The effect of change in pump wavelengths of RFA on Gain and NF of hybrid Amplifiers

\begin{tabular}{|c|c|c|c|c|c|c|}
\hline \multirow{2}{*}{$\begin{array}{c}\text { Case } \\
1\end{array}$} & $\begin{array}{l}\text { Wavelen } \\
\text { gth(nm) }\end{array}$ & 1428 & 1430 & 1432 & 1434 & \multirow{2}{*}{$\begin{array}{c}\text { Gain } \\
\text { Ratio: } \\
4.03 \\
\text { NF } \\
\text { Ratio:2.3 }\end{array}$} \\
\hline & $\begin{array}{c}\text { Power } \\
(\mathrm{mw})\end{array}$ & 200 & 200 & 100 & 100 & \\
\hline \multirow{2}{*}{$\begin{array}{c}\text { Case } \\
2\end{array}$} & $\begin{array}{l}\text { Wavelen } \\
\text { gth(nm) }\end{array}$ & 1432 & 1434 & 1436 & 1438 & \multirow{2}{*}{$\begin{array}{c}\text { Gain } \\
\text { Ratio: } \\
1.92 \\
\text { NF } \\
\text { Ratio:1.4 }\end{array}$} \\
\hline & $\begin{array}{c}\text { Power } \\
(\mathrm{mw})\end{array}$ & 200 & 200 & 100 & 100 & \\
\hline \multirow{2}{*}{$\begin{array}{c}\text { Case } \\
3\end{array}$} & $\begin{array}{l}\text { Wavelen } \\
\text { gth(nm) }\end{array}$ & 1434 & 1436 & 1438 & 1440 & \multirow{2}{*}{$\begin{array}{c}\text { Gain } \\
\text { Ratio: } \\
0.88 \\
\text { NF } \\
\text { Ratio:0.9 }\end{array}$} \\
\hline & $\begin{array}{c}\text { Power } \\
(\mathrm{mw})\end{array}$ & 200 & 200 & 100 & 100 & \\
\hline $\begin{array}{c}\text { Case } \\
4\end{array}$ & $\begin{array}{l}\text { Wavelen } \\
\text { gth(nm) }\end{array}$ & 1440 & 1442 & 1444 & 1446 & $\begin{array}{l}\text { Gain } \\
\text { Ratio: }\end{array}$ \\
\hline
\end{tabular}




\begin{tabular}{|c|c|c|c|c|c|c|}
\hline & $\begin{array}{c}\text { Power } \\
(\mathrm{mw})\end{array}$ & 200 & 200 & 100 & 100 & $\begin{array}{c}1.048 \\
\text { NF } \\
\text { Ratio:1.0 }\end{array}$ \\
\hline \multirow{2}{*}{$\begin{array}{c}\text { Case } \\
5\end{array}$} & $\begin{array}{l}\text { Wavelen } \\
\text { gth(nm) }\end{array}$ & 1448 & 1450 & 1452 & 1454 & \multirow{2}{*}{$\begin{array}{c}\text { Gain } \\
\text { Ratio: } \\
1.866 \\
\text { NF } \\
\text { Ratio:0.7 }\end{array}$} \\
\hline & $\begin{array}{l}\text { Power } \\
\text { (mw) }\end{array}$ & 200 & 200 & 100 & 100 & \\
\hline
\end{tabular}

Table 3: The effect of change in pump power with constant pump wavelengths of RFA on Gain and NF

\begin{tabular}{|c|c|c|c|c|c|c|}
\hline \multirow{2}{*}{$\begin{array}{c}\text { Case } \\
6\end{array}$} & $\begin{array}{c}\text { Waveleng } \\
\text { th } \\
(\mathrm{nm})\end{array}$ & 1434 & 1436 & 1438 & 1440 & \multirow{2}{*}{$\begin{array}{c}\text { Gain } \\
\text { Ratio: } \\
0.34 \\
\\
\text { NF } \\
\text { Ratio:0.5 }\end{array}$} \\
\hline & $\begin{array}{l}\text { Power } \\
(\mathrm{mw}) \\
\end{array}$ & 50 & 50 & 50 & 50 & \\
\hline \multirow{2}{*}{$\begin{array}{c}\text { Case } \\
7\end{array}$} & $\begin{array}{c}\text { Waveleng } \\
\text { th } \\
(\mathrm{nm})\end{array}$ & 1434 & 1436 & 1438 & 1440 & \multirow{2}{*}{$\begin{array}{c}\text { Gain } \\
\text { Ratio: } \\
0.43 \\
\\
\text { NF } \\
\text { Ratio:0.8 }\end{array}$} \\
\hline & $\begin{array}{l}\text { Power } \\
(\mathrm{mw})\end{array}$ & 100 & 100 & 100 & 100 & \\
\hline \multirow{2}{*}{$\begin{array}{c}\text { Case } \\
8\end{array}$} & $\begin{array}{c}\text { Waveleng } \\
\text { th } \\
(\mathrm{nm})\end{array}$ & 1434 & 1436 & 1438 & 1440 & \multirow{2}{*}{$\begin{array}{c}\text { Gain } \\
\text { Ratio: } \\
0.56 \\
\\
\text { NF } \\
\text { Ratio:1.1 }\end{array}$} \\
\hline & $\begin{array}{l}\text { Power } \\
(\mathrm{mw})\end{array}$ & 150 & 150 & 150 & 150 & \\
\hline \multirow{2}{*}{$\begin{array}{c}\text { Case } \\
9\end{array}$} & $\begin{array}{c}\text { Waveleng } \\
\text { th } \\
(\mathrm{nm})\end{array}$ & 1434 & 1436 & 1438 & 1440 & \multirow{2}{*}{$\begin{array}{c}\text { Gain } \\
\text { Ratio: } \\
0.69 \\
\\
\text { NF } \\
\text { Ratio:1.2 }\end{array}$} \\
\hline & $\begin{array}{l}\text { Power } \\
(\mathrm{mw})\end{array}$ & 200 & 200 & 200 & 200 & \\
\hline
\end{tabular}

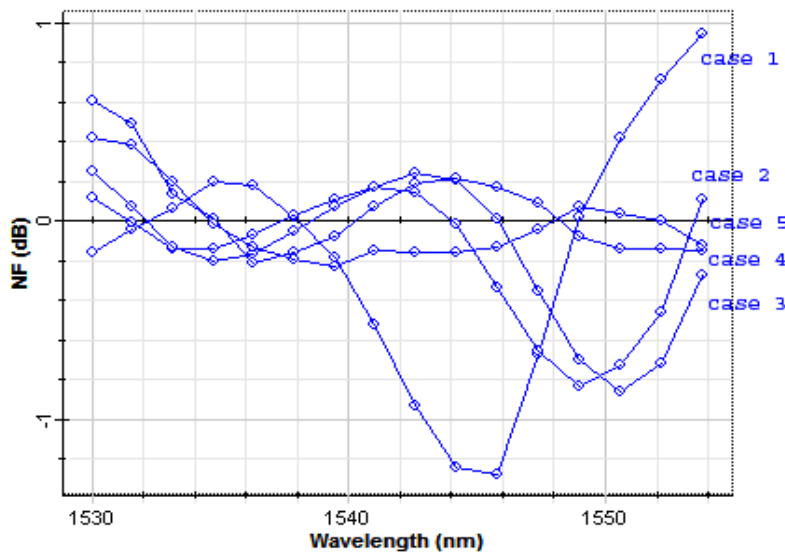

Figure 3 NF vs. Wavelength according to the cases given in table 2

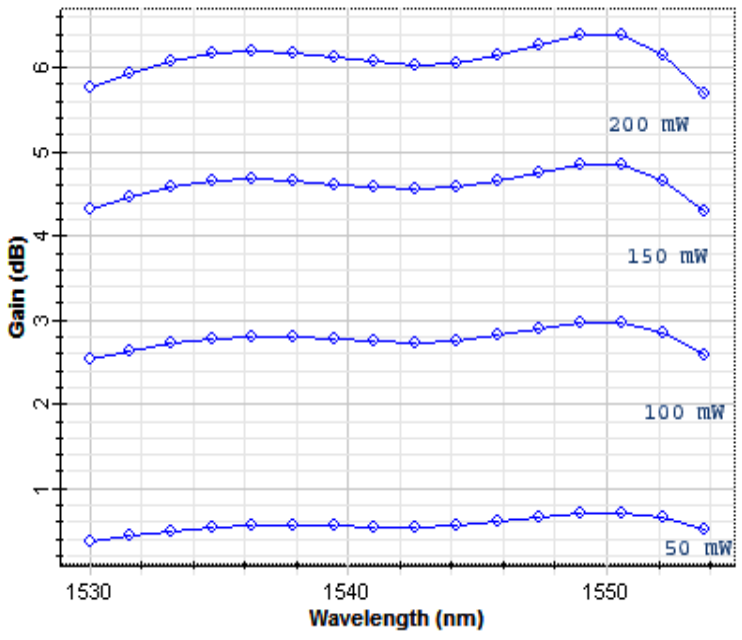

Figure 4: Gain Vs. Wavelength according to the cases given in table 3 .

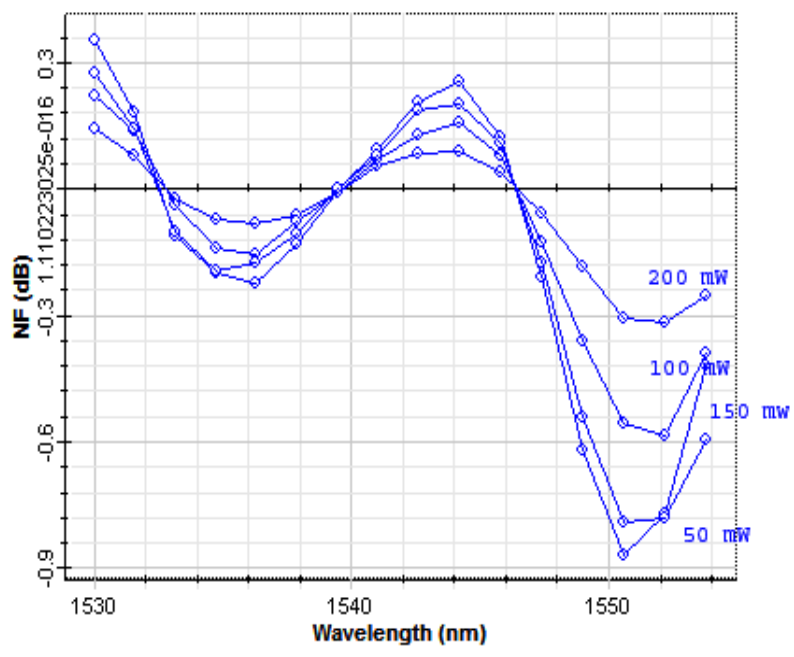

Figure 5: NF Vs. Wavelength according to the cases given in table 3 .

Figure 2: Gain Vs. Wavelength according to the cases given in table 2. 
Table 4: The effect of change in number of pumps with respect to different pump powers

\begin{tabular}{|c|c|c|c|c|c|c|c|c|}
\hline \multirow{2}{*}{ Case 11} & $\begin{array}{l}\text { Wavelength } \\
(\mathrm{nm})\end{array}$ & 1434 & 1435 & 1436 & 1437 & 1438 & 1440 & \multirow{2}{*}{$\begin{array}{l}\text { Gain Ratio: } 1.19 \\
\text { NF Ratio:1.25 }\end{array}$} \\
\hline & $\begin{array}{c}\text { Power } \\
(\mathrm{mw})\end{array}$ & 200 & 200 & 100 & 100 & 100 & 100 & \\
\hline \multirow{2}{*}{ Case 12} & $\begin{array}{l}\text { Wavelength } \\
(\mathrm{nm})\end{array}$ & 1434 & 1435 & 1436 & 1437 & 1438 & 1440 & \multirow{2}{*}{$\begin{array}{l}\text { Gain Ratio: } 1.68 \\
\text { NF Ratio: } 1.55\end{array}$} \\
\hline & $\begin{array}{c}\text { Power } \\
(\mathrm{mw})\end{array}$ & 300 & 300 & 300 & 100 & 100 & 100 & \\
\hline \multirow{2}{*}{ Case 13} & $\begin{array}{l}\text { Wavelength } \\
(\mathrm{nm})\end{array}$ & 1434 & 1435 & 1436 & 1437 & 1438 & 1440 & \multirow{2}{*}{$\begin{array}{l}\text { Gain Ratio: } 1.462 \\
\text { NF Ratio: } 1.392\end{array}$} \\
\hline & $\begin{array}{c}\text { Power } \\
\text { (mw) }\end{array}$ & 250 & 150 & 250 & 50 & 50 & 100 & \\
\hline \multirow{2}{*}{ Case 14} & $\begin{array}{c}\text { Wavelength } \\
(\mathrm{nm})\end{array}$ & 1434 & 1435 & 1436 & 1437 & 1438 & 1440 & \multirow{2}{*}{$\begin{array}{l}\text { Gain Ratio: } 3.82 \\
\text { NF Ratio:2.16 }\end{array}$} \\
\hline & $\begin{array}{c}\text { Power } \\
(\mathrm{mw})\end{array}$ & 300 & 300 & 200 & 100 & 150 & 150 & \\
\hline
\end{tabular}

\section{CONCLUSIONS}

The following points are there to state the conclusions:

- Gain flattening is obtained at pump wavelength 100 $\mathrm{nm}$ lesser to the wavelength to be amplified.

- Low pump power at high wavelengths and high pump power at low wavelengths give better results for gain flattening.

- The Noise figure $<4 \mathrm{dBm}$ throughout the system so it's tolerable.

- Increase in pump powers increases the value of gain while increasing the gain variation as well. Noise Figure is not that much affected with the increase in pump power.

- Four pump RFA is better than the 6 pump RFA as the gain flattening is more in four pump RFA as in case 9 the gain variation is the best according to the value of gain i.e. 0.69 with permissible noise figure ratio.

Best gain equalization is achieved in case 9 with pump wavelengths of 1434, 1436, 1438 and 1440. The gain ratio is reduced to 0.69 with value of NF below $3 \mathrm{~dB}$ and value of gain better than the other pump powers which although provide less gain variation but decreases the value of gain significantly.

\section{FUTURE WORK}

- Results can be modified with the help of changing or optimizing the pump wavelengths in accordance with different pump powers in RFA. Also Different band of frequencies can be used to acquire gain flattening and increased bandwidth with the variation in the input power.

- No of pump lasers can be decreased or increased to get more gain equalization.

\section{REFERENCES}

[1] Yan Sun, Atul K. Srivastava, Jianhui Zhou and James W. Sulhoff, "Optical Fiber Amplifiers with WDM Optical Networks," Bell Labs Technical Journal Jan-March, 1999.

[2] M. M. J. Martini, C. E. S. Castellani, M.J. Pontes, M. R. N. Ribeiro and H. J. Kalinowski, "Multi-Pump Optimization for Raman plus EDFA Hybrid Amplifiers under Pump Residual Recycling" SBMO/IEEE MTT-S International Microwave and Optoelectronics Conference(IMOC 2009)

[3] Hossein Afkhami, Alireza Mowla, Nosrat Granpayeh and Azadeh Rastegari Hormozi, "Wideband Gain Flattened Hybrid Erbium-doped Fiber Amplifier/Fiber Raman Amplifier" Journal of the Optical Society of Korea Vol. 14, No. 4, December 2010, pp. 342-350.

[4] Simranjeet Singh and R.S. Kaler, "Performance Analysis of $64 \times 10$ Gbps and $96 \times 10$ Gbps DWDM with hybrid optical amplifier for different Modulation Techniques," Optik 123(2012) 2199-2203.

[5] R.S Kaler, "Optimization of Hybrid Raman/fiber doped fiber for multi-terabits WDM system" Optik 124(2013) $575-578$

[6] Ramandeep Kaur, Rajneesh Randhawa and R.S. Kaler, "Performance Evaluation of optical fiber 16x12, 32x10,64x10 Gbps WDM System, ”Optik 124(2013) 693-700.

[7] V. Bobrovs, S. Olonkins, A. Alsevska, L. Gegere and G. Ivanovs, "Comparative performance of Raman- SOA and Raman-EDFA hybrid optical amplifiers in DWDM transmission system" International Journal of Physical Sciences Vol. 8(39), pp. 1898-1906, 23 October 2013

[8] Simranjeet Singh and R.S. Kaler, "Placement of Hybrid Optical Amplifier in Fiber Optical Systems," Optik 123 (2012) 1636 - 1639

[9] Ha-Yin Hsu, Yi-Lin Yu, Shien Kuei Liaw, Ren-Yang Liu and Chow Shing Shin, "Theoretical and experimental Study of multifunction $\mathrm{C}+\mathrm{L}$ Band Hybrid fiber amplifiers" Optics \& Laser Technology 56 (2014)307-31 